\title{
Microwave Induced Facile One-pot Access to Diverse 2-cyanobenzothiazole-A Key Intermediate for the Synthesis of Firefly Luciferin
}

\author{
Neelam P. Prajapati, Rajesh H. Vekariya, Hitesh D. Patel* \\ Department of Chemistry, School of Sciences, Gujarat University, Ahmedabad, India \\ Mobile (O) +91-079-26300969, (Fax) +91-079-26308545 \\ *E-mail address: drhiteshpatel1@gmail.com
}

\begin{abstract}
An eco-friendly one-step preparation of various substituted 2-cyanobenzothiazole by condensation of corresponding substituted ortho-aminothiophenol with ethyl cyanoformate, employing an effective amount of Lawesson's reagent, under microwave irradiation (MWI) and solvent free conditions is presented. The structures of the compounds were elucidated with the aid of elemental analysis, IR, ${ }^{1} \mathrm{H}-\mathrm{NMR}$ and mass spectral data. The targeted various substituted 2cyanobenzothiazole are obtained in good yields and high purity.
\end{abstract}

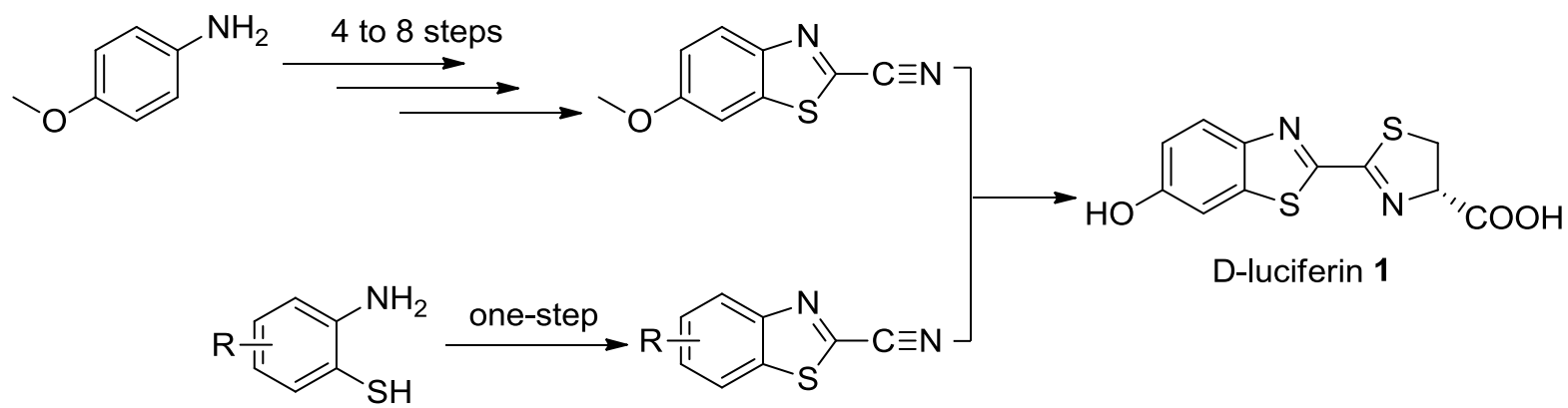

Keywords: Benzothiazoles; Lawesson's reagent; microwave; one-step reaction; D-luciferin

\section{INTRODUCTION}

D-luciferin [(S)-2-(6'-hydroxy-2'-benzothiazolyl)thiazoline-4-carboxylic acid] is the natural substrate of the enzyme luciferase (Luc), that catalyzes the production of the typical yellow-green light of fireflies [1]. Fireflies are only a part of the big family of bioluminescent insects that can emit light with wavelengths going from yellow-green $(560 \mathrm{~nm})$ to red $(620$ $\mathrm{nm})$ [2]. All the enzymes use the same substrate, i.e. D-luciferin $\mathbf{1 .}$ 


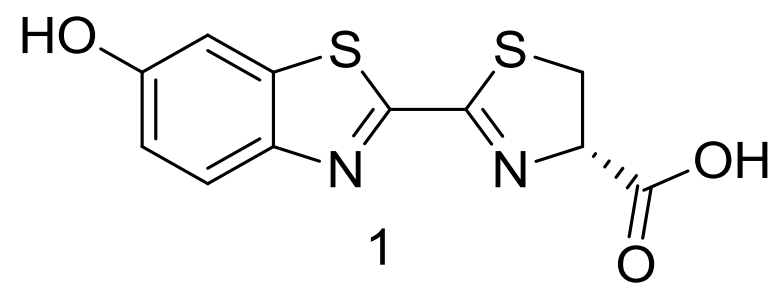

Figure 1. Structure of D-luciferin.

Firefly luciferases can modulate the proportion of green and red bioluminescence through a pH-sensitive mechanism [3]. The luciferase from the North American firefly Photinus pyralis (PpyLuc) is a well characterized enzyme that finds a large number of applications in mammalian cells. PpyLuc has been used in living animals as a transgenic marker or as a tag for cells that have been transplanted [4]. Due to its bioluminescence characteristics, PpyLuc is at present the most used enzyme in optical molecular imaging [5] and is the most studied enzyme of the luciferase family.

The importance of green chemistry in organic synthesis has encouraged scientists to explore the use of microwave irradiation for the organic synthesis. Over the last few years, microwave irradiation (MWI) has emerged a great energy source for the wide range of organic transformation with short reaction time and high yield of the products with high purity [6-19]. Hence, a study has been undertaken using microwave irradiation for the condensation of ortho-aminothiophenol with ethyl cyanoformate using Lawesson's reagent under solvent and catalyst free condition (Scheme 4).

During the literature search, we have found out that there are only a few numbers of synthetic path-ways available for the synthesis of D-luciferin. These all possible synthetic pathways for the synthesis of D-luciferin are described below.

\section{1. Synthesis of D-luciferin from $p$-anisidine 4}

The chemical structure of D-luciferin, isolated from firefly tails, was proposed in 1961 [20] and later confirmed by synthesis (Scheme 1) [21]. The overall yield of D-luciferin 1 from $p$-anisidine 4 is $9 \%$ through nine steps. 2-cyano-6- hydroxybenzothiazole $\mathbf{1 2}$ is the key intermediate for the synthesis of D-luciferin $\mathbf{1}$.

In this procedure, $p$-anisidine $\mathbf{4}$ is the starting material that, through intermediates $\mathbf{5}$ and 6, is transformed into the thioacid 7, in turn cyclized to 6- methoxybenzothiazole-2carboxylic acid 8. From this benzothiazole derivative, 2-cyano-6- hydroxybenzothiazole 12 is prepared in four steps. Compound $\mathbf{1 2}$ is the key intermediate for the synthesis of $\mathbf{1}$ that can be obtained almost quantitatively by reaction with D-cysteine, in situ produced by reduction of D-cystine. 


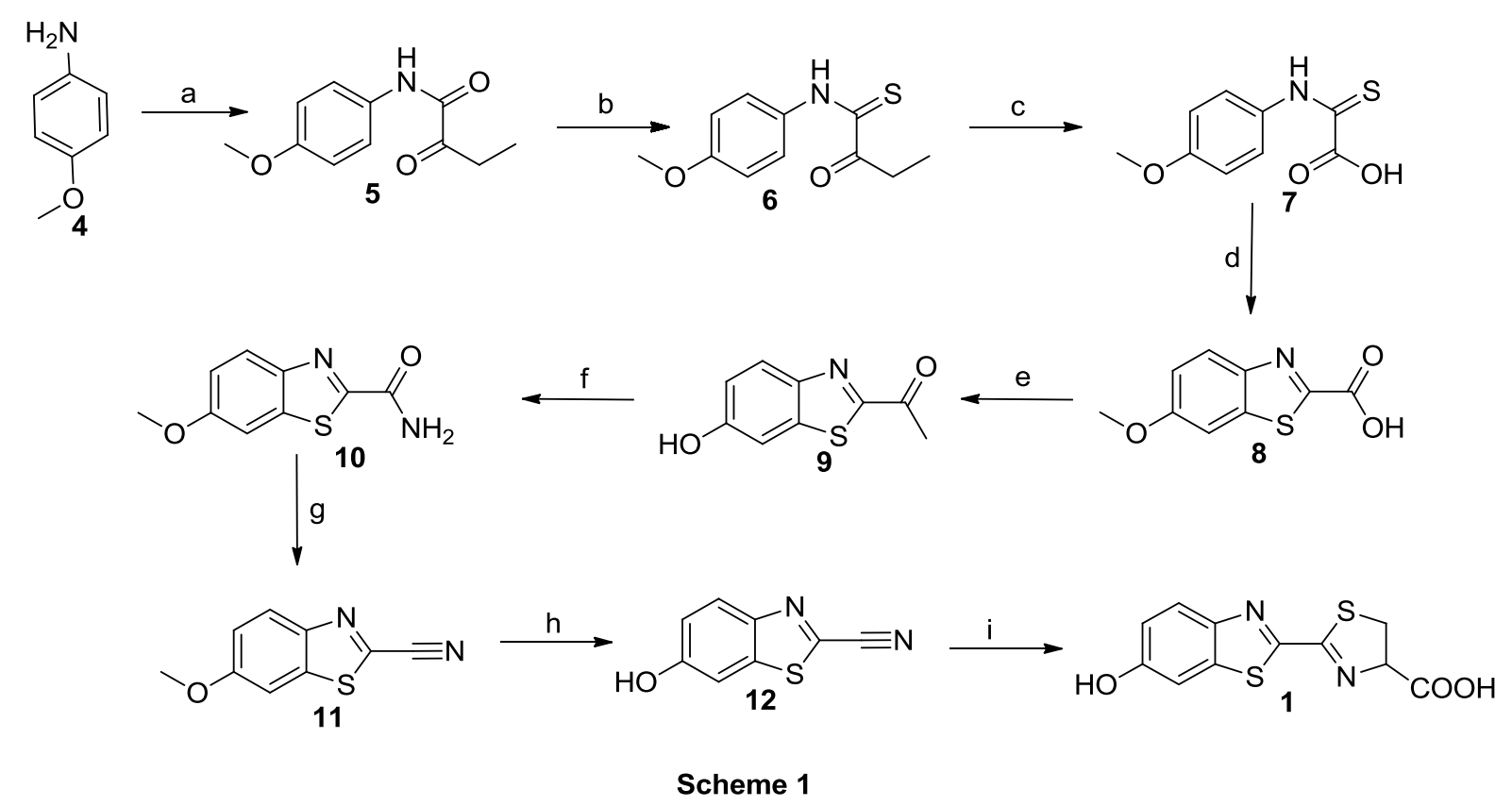

Reagents and Conditions: (a) ethyl oxalate, $180{ }^{\circ} \mathrm{C}, 5 \mathrm{~min}, 58 \%$; (b) $\mathrm{P}_{2} \mathrm{~S}_{5}$, reflux, 40 min; (c) $\mathrm{NaOH}, 0{ }^{\circ} \mathrm{C}$ then $\mathrm{HCl}$; (d) $\mathrm{K}_{3} \mathrm{Fe}(\mathrm{CN})_{6} / \mathrm{OH}^{-},<10^{\circ} \mathrm{C}, 15 \mathrm{~min}$; $(76 \%$ crude, no isolation in steps b-d); (e) $\mathrm{CH}_{2} \mathrm{~N}_{2}, 0{ }^{\circ} \mathrm{C}, 15 \mathrm{~min}, 40 \%$; (f) anhydrous $\mathrm{NH}_{3} / \mathrm{MeOH}$, heat, $30 \mathrm{~min}, 100 \%$; (g) $\mathrm{POCl}_{3}$, reflux, $15 \mathrm{~min}, 56 \%$; (h) $\mathrm{PyHCl}, 200{ }^{\circ} \mathrm{C}, 1 \mathrm{~h}, 62 \%$; (i) D-cysteine (in situ from Dcystine/liquid $\mathrm{NH}_{3} / \mathrm{Na}$, r.t., $10 \mathrm{~min}$ ) and 12 in $\mathrm{H}_{2} \mathrm{O} / \mathrm{MeOH}$, r.t., 0.5 h, 94\%.

\subsection{Synthesis of D-luciferin from 4-methoxythioxanilinamide 13}

This experimental protocol has been applied to the preparation of 5-10 g of D-luciferin 1 [23]. According to Seto et al., [22] 6- methoxybenzothiazole-2-carboxyamide $\mathbf{1 0}$ is prepared from the 4-methoxythioxanilinamide 13 by oxidative cyclization with alkaline $\mathrm{K} 3[\mathrm{Fe}(\mathrm{CN}) 6]$ (Scheme 2). The transformation of compound $\mathbf{1 0}$ into the nitrile $\mathbf{1 1}$ has been carried out essentially as reported by White et al. [21]

The preparation of 4-methoxythioxanilinamide 13, according to Seto et al. can be carried out in good yields from $p$-anisidine $\mathbf{4}$ and carbamoylthiocarbonylthioacetic acid $\mathbf{1 4}$. However, this compound is unstable and has to be prepared in situ, as described in detail by Bowie [23]. The experimental procedure allows to prepare compound $\mathbf{1 1}$ from $p$-anisidine 4 with an overall 39\% yield. 
<smiles>Cc1ccccc1</smiles><smiles>COc1ccc(NC(=S)C(N)=O)cc1</smiles>

14

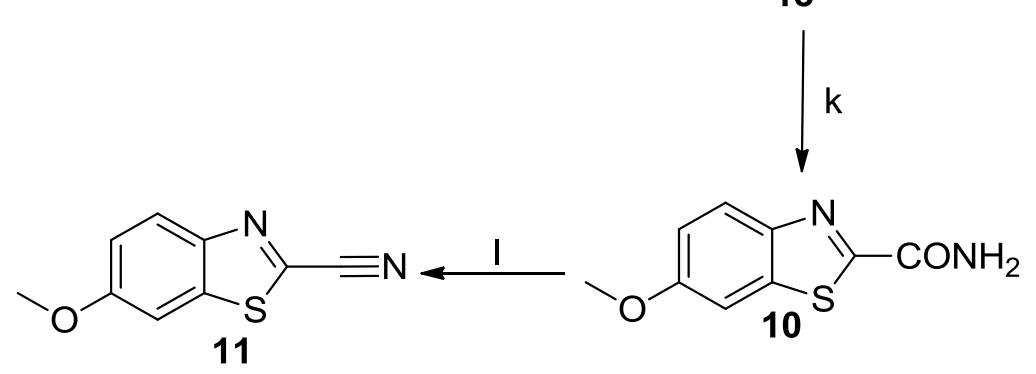

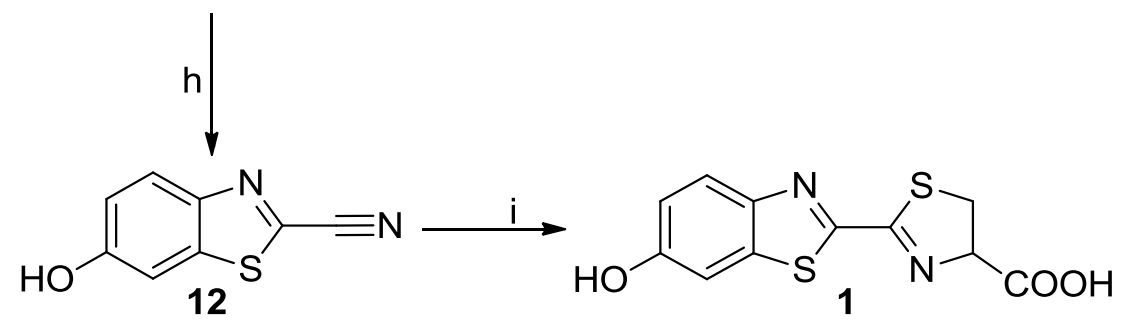

Scheme 2

Reagents and Conditions: (j) aq. $\mathrm{MeOH}$; (k) $\mathrm{K}_{3}\left[\mathrm{Fe}(\mathrm{CN})_{6}\right] / \mathrm{OH}^{-}$, r.t., $1 \mathrm{~h}, 60 \%$; (l) $\mathrm{POCl}_{3}$, reflux, $1.5 \mathrm{~h}, 67 \%$ (m) aq. $\mathrm{KOH}, \mathrm{H}_{2} \mathrm{~S}$; (n) $\mathrm{ClCH}_{2} \mathrm{COOH}$.

\section{2. Synthesis of D-luciferin by following a Sand-Meyer approach from 2-amino-6- methoxybenzothiazole 15}

According to another synthetic approach, 2-amino-6-methoxybenzothiazole 15 can be prepared from $p$-anisidine 4 [24] and different routes can lead to 2-cyano-6hydroxybenzothiazole 11 using a classical Sand-Meyer reaction.

In a first synthesis, [24,25] 2-chloro-6- methoxybenzothiazole 16 was prepared by reaction of compound $\mathbf{1 5}$ with nitrous acid and $\mathrm{HCl}$. Reaction of compound $\mathbf{1 6}$ with $\mathrm{KCN}$ in DMSO afforded the nitrile 11 (Scheme 4). Conditions of formation of 2-chloro derivative 16 were improved using isoamyl nitrite and copper (II) chloride in polyethylene glycol 200 [26] as solvent and yields were improved to $56 \%$. More recently, the Sand-Meyer reaction was carried out by direct introduction of cyanide with $\mathrm{CuCN} / \mathrm{KCN}$ [27] and following this approach a $41 \%$ yield was obtained. 


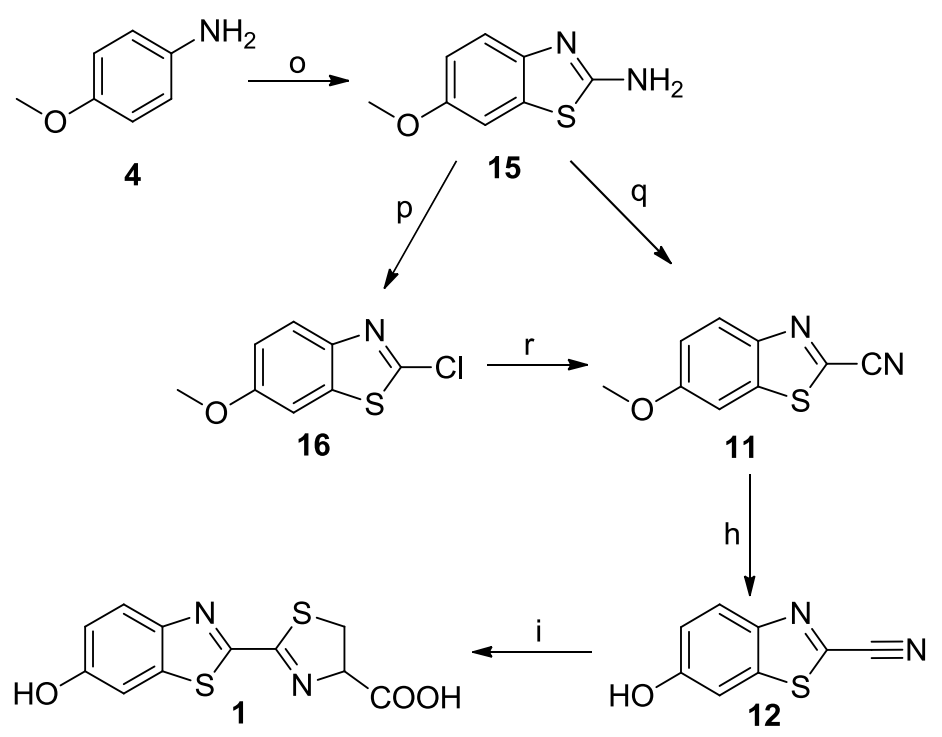

Scheme 3

Reagents and Conditions: (o) $\mathrm{KSCN}, \mathrm{Br}_{2} / \mathrm{AcOH}, 35^{\circ} \mathrm{C}, 10 \mathrm{~h}, 87 \%$; (p) $\mathrm{HNO}_{2}, \mathrm{HCl}, 0$ $60{ }^{\circ} \mathrm{C}, 2 \mathrm{~h}, 35-45 \%$; (q) $\mathrm{HNO}_{2}, \mathrm{CuCN} / \mathrm{KCN}, 0{ }^{\circ} \mathrm{C}, 1 \mathrm{~h}, 41 \%$; (r) KCN/DMSO, $140{ }^{\circ} \mathrm{C}, 1 \mathrm{~h}$, $40 \%$.

\section{GENERAL REACTION SCHEME (PRESENT WORK)}

We here in present an eco-friendly one-step preparation of various substituted 2cyanobenzothiazole by condensation of corresponding substituted ortho-aminothiophenol with ethyl cyanoformate, employing an effective amount of Lawesson's Reagent, under microwave irradiation (MWI) and solvent free conditions.

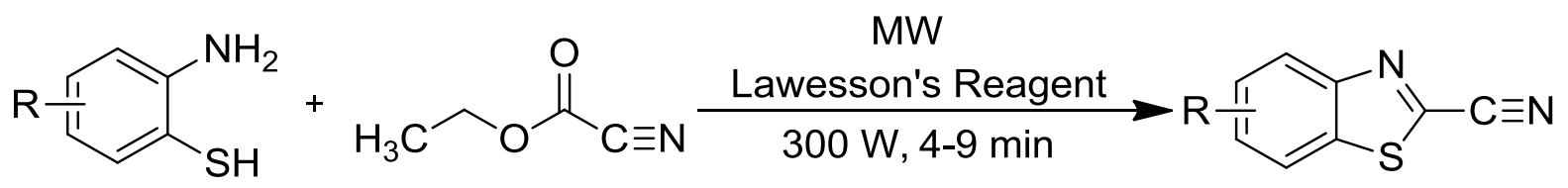

Scheme 4. Synthetic route for 2-cyanobenzothiazole derivatives.

\section{RESULT AND DISCUSSION}

Some mechanistic aspects involved in this reaction are still under study (Figure 2). It was supposed that ortho-aminothiophenol and carboxylic ester were activated by Lawesson's reagent (LR) and formed adduct. Finally the ethanol molecule was eliminated from adduct and produced 2-cyanobenzothiazole derivatives in excellent yield. The title compounds, 2cyanobenzothiazole derivatives (Table 1) were synthesized via cyanobenzothiazole by condensation of substituted ortho-aminothiophenols with ethyl cyanoformate, employing the catalytic amount of Lawesson's reagent, under microwave irradiation (MWI) and solvent free conditions. 


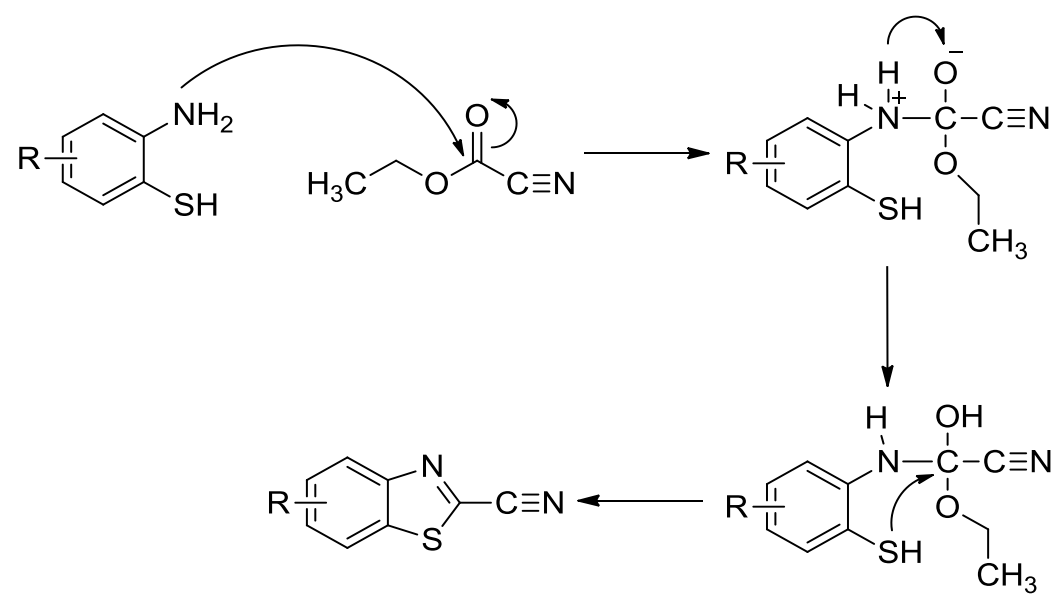

Figure 2. Proposed reaction mechanism.

Here, ortho-aminothiophenols undergoes condensation reaction with ethyl cyanoformate, employing an effective amount of LR under microwave irradiation (MWI), afforded title compounds in excellent yield within short period of time (4-9 min.). In a typical example we have reacted 1.0 equiv. of ortho-aminothiophenols with 1.0 equiv. of ethyl cyanoformate and 0.35 equiv. of Lawesson's reagent under microwave irradiation $(300 \mathrm{~W})$ at $190^{\circ} \mathrm{C}$. It was noted that 0.35 equiv. Lawesson's reagent was sufficient for this transformation as compared to lower amount of Lawesson's reagent. It was interesting to mention that at 300 $\mathrm{W}$ (microwave irradiation power), the reaction was completed in shorter time as compared to lower irradiation power. In addition, it was also observed that, high power (Up to $300 \mathrm{~W}$ ) of microwave irradiation does not increase the yield of product. Both the electron-withdrawing group and electron-releasing groups on the ortho-aminothiophenols showed equally efficiency. The structures of products were characterized unambiguously by elemental and spectroscopic (IR, Mass, 1H-NMR) analysis.

Table 1. Synthesis of benzo[d]thiazole-2-carbonitrile derivatives using ortho-aminothiophenols ( 1 equiv.), ethyl cyanoformate ( 1 equiv.) and 0.35 equiv. of Lawesson's reagent.

No. 2-aminohiophenol

${ }^{\mathrm{a}}$ Yields refer to isolated pure products 


\section{MATERIALS AND METHOD}

Chemicals used in this reaction such as Ethyl cyanoformate were of analytical grade and purchased from Sigma-Aldrich, USA. The various substituted ortho-aminothiophenols were synthesised in the laboratory using the previously reported method [28]. Lawesson's Reagent was purchased from Spectrochem Pvt. Ltd., Mumbai, India.

The reactions were assayed by thin layer chromatography (TLC) and terminated as judged by the consumption of starting material. Analytical thin-layer chromatography (TLC) was performed on silica gel G 60 F254 (Merck) plates and eluted with the appropriate solvent ratios $10 \%$ Hexane- $\mathrm{CH}_{2} \mathrm{Cl}_{2}(\mathrm{v} / \mathrm{v})$. The melting points were recorded in Optimelt Automated Melting point System and were uncorrected. IR spectra were recorded on a Perkin-Elmer 377 spectrophotometer, ${ }^{1} \mathrm{H}$ NMR spectra was measured in Bruker AV $400 \mathrm{MHz}$ using $\mathrm{CDCl}_{3}$ as a solvent and TMS as an internal standard. Mass spectra was recorded on Advion Expression CMS, USA. Elemental analysis was performed on the Vario MICRO cube, elementary CHN analyzer serial no.: 15084053. Here we have used the CEM Discover microwave system for synthesis. Its model no.: 908010 and made by CEM Matthews. Inc, USA.

General procedure for the synthesis of Benzo[d]thiazole-2-carbonitrile derivatives: A mixture of Ethyl cyanoformate $(136 \mathrm{mg}, 1 \mathrm{mmol}), 2$-amino-5-methoxybenzenethiol (109 $\mathrm{mg}, 1 \mathrm{mmol})$ and Lawesson's Reagent $(141 \mathrm{mg}, 0.35 \mathrm{mmol})$ was irradiated in an open vessel with microwaves in a monomode oven (Discover CEM, $300 \mathrm{~W}$ and temperature control set at $190{ }^{\circ} \mathrm{C}$ measured with an IR sensor) for $4 \mathrm{~min}$. The crude was dissolved in $\mathrm{CH}_{2} \mathrm{Cl}_{2}(30 \mathrm{~mL})$ and washed with $10 \%$ aq $\mathrm{NaOH}(2 \times 20 \mathrm{~mL})$, dried $\left(\mathrm{Na}_{2} \mathrm{SO}_{4}\right)$ and evaporated. The residual red-brown solid was purified by silica-gel TLC with $10 \%$ Hexane- $\mathrm{CH}_{2} \mathrm{Cl}_{2}$ to give the nitrile (188 mg, 90\%) as pale yellow needles, which was used for the next step without further purification. An analytical sample was obtained by recrystallizing the product from $\mathrm{CH}_{2} \mathrm{Cl}_{2}$ Hexane; mp $129-130^{\circ} \mathrm{C}$.

The other four derivatives of substituted 2-cyano benzothiazole were also synthesised using this method described above. They are conformed by spectral as well as analytical analysis.

\section{6-Methoxybenzo[d]thiazole-2-carbonitrile: (1)}

Pale yellow needles; M.P. 129-130 ${ }^{\circ} \mathrm{C}$; Yield: 90\%; IR (vmax): 2231, 1325, 1252, 1132, 1029 , $624 \mathrm{~cm}^{-1}$; Mass $(\mathrm{m} / \mathrm{z}): 191.2(\mathrm{M}+1)^{+}$(Base peak), $192.4(\mathrm{M}+2)^{+} ;{ }^{1} \mathrm{H}-\mathrm{NMR}(\mathrm{ppm}):\left(\mathrm{CDCl}_{3}\right) \delta$ $8.690(1 \mathrm{H}, \mathrm{d}, J=9.0), 8.269(1 \mathrm{H}, \mathrm{dd}, J=9.0), 8.050(1 \mathrm{H}, \mathrm{d}, J=2.4), 3.349(3 \mathrm{H}, \mathrm{s})$; Elemental Analysis: Calculated: C, 56.83; H, 3.18; N, 14.73; S, 16.86\%; Found: C, 56.55; H, 3.22; N, 14.97; S, 16.88\%.

\section{Benzo[d]thiazole-2-carbonitrile: (2)}

M.P. $105{ }^{\circ} \mathrm{C}$; Yield: 83\%; IR ( $\left.v_{\max }\right): 2250,1331,1258,617 \mathrm{~cm}^{-1}$; Mass $(\mathrm{m} / \mathrm{z}): 161.1(\mathrm{M}+1)^{+}$ (Base peak), $162.1(\mathrm{M}+2)^{+} ;{ }^{1} \mathrm{H}-\mathrm{NMR}(\mathrm{ppm}):\left(\mathrm{CDCl}_{3}\right) \delta 8.28(1 \mathrm{H}, \mathrm{d}, J=9.2), 8.08(1 \mathrm{H}, \mathrm{d}$, $J=8.7), 7.63$ (2H, m); Elemental Analysis: Calculated: C, 59.98; H, 2.52; N, 17.49; S, 20.02\%; Found: C, 59.76; H, 2.68; N, 17.34; S, 20.15\%

6-Hydroxybenzo[d]thiazole-2-carbonitrile: (3)

M.P. $134{ }^{\circ} \mathrm{C}$; Yield: $71 \%$; IR $\left(v_{\max }\right): 3315,2231,1325,1252,1132,1029,624 \mathrm{~cm}^{-1}$; Mass $(\mathrm{m} / \mathrm{z}): 177.2(\mathrm{M}+1)^{+}$(Base peak), $178(\mathrm{M}+2)^{+} ;{ }^{1} \mathrm{H}-\mathrm{NMR}(\mathrm{ppm}):\left(\mathrm{CDCl}_{3}\right) \delta 7.57(1 \mathrm{H}, \mathrm{d}$, $J=8.73), 7.17(1 \mathrm{H}, \mathrm{s}), 6.68(1 \mathrm{H}, \mathrm{d}, J=2.43), 5.14(1 \mathrm{H}, \mathrm{s})$; Elemental Analysis: Calculated: C, 54.53; H, 2.29; N, 15.90; S, 18.20\%; Found: C, 54.87; H, 2.02; N, 16.05; S, 17.98\%.

5-Chlorobenzo[d]thiazole-2-carbonitrile: (4)

M.P. $156^{\circ} \mathrm{C}$; Yield: $62 \%$; IR $\left(v_{\max }\right): 2231,1325,1252,680 \mathrm{~cm}^{-1}$; Mass $(\mathrm{m} / \mathrm{z}): 195.1(\mathrm{M}+1)^{+}$ (Base peak), $196.1(\mathrm{M}+2)^{+} ;{ }^{1} \mathrm{H}-\mathrm{NMR}(\mathrm{ppm}):\left(\mathrm{CDCl}_{3}\right) \delta 8.30(1 \mathrm{H}, \mathrm{d}, J=9.25), 7.98(1 \mathrm{H}, \mathrm{d}$, 
$J=9.0), 7.52(1 \mathrm{H}, \mathrm{dd}, J=9.4)$; Elemental Analysis: Calculated: C, 49.37\%; H, 1.55\%; N, 14.39; S, 16.47\%; Found: C, 49.62\%; H, 1.45\%; N, 14.21; S, 16.54\%.

\section{$\mathrm{N}$-(2-cyanobenzo[d]thiazol-6-yl)acetamide (5)}

M.P. $263{ }^{\circ} \mathrm{C}$; Yield: $67 \%$; IR $\left(v_{\max }\right)$ : 2231, 1645, 1325, 1252, 1132, 1029, $624 \mathrm{~cm}^{-1}$; Mass $(\mathrm{m} / \mathrm{z}): 218.2(\mathrm{M}+1)^{+}$(Base peak), $219.1(\mathrm{M}+2)^{+} ;{ }^{1} \mathrm{H}-\mathrm{NMR}(\mathrm{ppm}):\left(\mathrm{CDCl}_{3}\right) \delta 8.45(1 \mathrm{H}, \mathrm{d}$ $J=9.1), 7.75(2 \mathrm{H}, \mathrm{m}), 7.17(1 \mathrm{H}, \mathrm{s}), 2.19(3 \mathrm{H}, \mathrm{s})$; Elemental Analysis: Calculated: C, 55.29; H, $3.25 ; \mathrm{N}, 19.34$; S, 14.73\%; Found: C, 55.09; H, 3.33; N, 19.12; S, 14.70\%.

\section{CONCLUSIONS}

In this article, we have elaborated the initial efforts made toward the sighting of highly important Benzo[d]thiazole-2-carbonitrile derivatives which were synthesized by green and efficient method. It is interesting to note that the conventional procedure have six to ten steps for the preparation of Benzo[d]thiazole-2-carbonitrile derivatives, while in present work it is prepared in two steps only. The present procedure offers various advantages such as a very short reaction time, microwave assisted synthesis, simple work-up procedure, excellent yield of products and step-down synthesis by green chemistry protocol.

\section{Acknowledgement}

The authors are thankful to the Department of Chemistry, Gujarat University, Ahmedabad, for providing the necessary facilities and also thankful to UGC-Info net \& INFLIBNET Gujarat University for providing esource facilities. One of us R.H.V. is thankful to UGC-BSR (F.7-74/2007 (BSR)) for financial assistance.

\section{References}

[1] E. H. White, E. Rapaport, H. H. Seliger, T. A. Hopkins, Bioorg. Chem. 1 (1971) 92-122.

[2] V. R. Viviani, Cell. Mol. Life. Sci. 59 (2002) 1833-1850.

[3] H. H. Seliger, W. D. McElroy, Proc. Natl. Acad. Sci. USA. 52 (1964) 75-81.

[4] C. H. Contag, M. H. Bachmann, Annu. Rev. Biomed. Eng. 4 (2002) 235-260.

[5] G. D. Lüker, K. E. Lüker, J. Nucl. Med. 49 (2008) 1-4.

[6] R. A. Irgashev, A. A. Karmatsky, P. A. Slepukhin, G. L. Rusinov, V. N. Charushin, Tetrahedron Lett. 54 (2013) 5734-5738.

[7] T. M. Potewar, K. T. Petrova, M. T. Barros, Carbohydr. Res. 379 (2013) 60-67.

[8] R. C. Lian, M. H. Lin, M. H. Liao, J. J. Fu, Y. C. Wu, F. R. Chang, C. C. Wu, M. J. Wu, P. S. Pan, Tetrahedron. 70 (2014) 1800-1804.

[9] M. Y. Mentese, H. Bayrak, Y. Uygun, A. Mermer, S. Ulker, S. A. Karaoglu, N. Demirbas, Eur. J. Med. Chem. 67 (2013) 230-242.

[10] F. Messina, O. Rosati, Curr. Org. Chem. 17 (2013) 1158-1178.

[11] P. Appukkuttan, V.P. Mehta, E. V. Van der Eycken, Chem.Soc.Rev. 39 (2010) 14671477.

[12] X. Zhang, H. Jiang, D. Ye, H. Sun, H. Liu, Green Chem. 11 (2009) 1881-1888. 
[13] B. Maiti, K. Chanda, M. Selvaraju, C. C. Tseng, C. M. Sun, ACS Comb. Sci. 15 (2013) 291-297.

[14] A. Walia, S. Kang, R. B. Silverman, J. Org. Chem. 78 (2013) 10931-10937.

[15] E.F. Dimauro, J. M. Kennedy, J. Org. Chem. 72 (2007) 1013-1016.

[16] R. B. Sparks, A. P. Combs, Org. Lett., 6 (2004) 2473-2475.

[17] H. D. Patel, S. M. Divatia, E. D. Clercq, Indian J. Chem,. 52B (2013) 535-545.

[18] S. M. Prajapati, R. H. Vekariya, K. D. Patel, S. N. Panchal, H. D. Patel, D. P. Rajani, S. Rajani, Int. Lett. Chem. Phys. Astron. 20 (2014) 195-210.

[19] R. H. Vekariya, S. N. Panchal, K. D. Patel, H. D. Patel, Curr. Microwave Chem. (2015) DOI: $10.2174 / 2213335601666141023223657$.

[20] E. H. White, F. McCapra; G. F. Field, W. D. McElroy, J. Am. Chem. Soc. 83 (1961) 2402-2403.

[21] E. H. White, F. McCapra, G. F. Field, J. Am. Chem. Soc. 85 (1963) 337-343.

[22] S. Seto, K. Ogura, Y. Nishiyama, Bull. Chem. Soc. Jpn. 36 (1963) 331-332.

[23] L. Bowie, J. Method Enzymol. 57 (1978) 15-28.

[24] G. C. Stuckwisch, J. Am. Chem. Soc. 71 (1949) 3417-3417.

[25] E. H. White, H. Woelther, G. F. Field, W. D. McElroy, J. Org. Chem. 30 (1965) 23442348.

[26] N. Suzuki, T. Nomoto, N. Kanamori, B. Yoda, A. Saeki, Biosci. Biotech. Biochem. 57 (1993) 1561-1562.

[27] Y. Toya, M. Takagi, H. Nakata, N. Suzuki, M. Isobe, T. Goto, Bull. Chem. Soc. Jpn. 65 (1992) 392-395.

[28] P. K. Sharma, B. S. Rathore, M. Kumar, A. Fogla, Res Chem Intermed 37 (2011) $1103-$ 1111. 